\title{
Erratum to: Loss of plakoglobin promotes decreased cell-cell contact, increased invasion, and breast cancer cell dissemination in vivo
}

Ingunn Holen ${ }^{1}$, Jacob Whitworth', Faith Nutter ${ }^{1}$, Alyson Evans' ${ }^{1}$, Hannah K. Brown ${ }^{1}$, Diane V. Lefley ${ }^{1}$, Ivana Barbaric ${ }^{2}$, Mark Jones ${ }^{2}$ and Penelope D. Ottewell ${ }^{1,3^{*}}$

\section{Erratum}

After the publication of this study [1] an error was detected in Fig. 2e. The same image was accidently used for beta-catenin staining of MCF7 2A-1 and T47D 2A-4. This error does not affect the findings or conclusions of the article. The corrected figure is shown below and we apologise for this mistake.

\footnotetext{
Author details

${ }^{1}$ Academic Unit of Clinical Oncology, Beech Hill Road, Sheffield, UK. ${ }^{2}$ Centre for Stem Cell Research, Biomedical Sciences, Western Bank, University of Sheffield, Sheffield, UK. ${ }^{3}$ Academic Unit of Clinical Oncology, CR-UKMCR Sheffield Cancer Research Centre, University of Sheffield, Sheffield S10 2RX, UK.
}

Received: 6 March 2017 Accepted: 6 March 2017

Published online: 28 March 2017

\section{Reference}

1. Holen I, Whitworth J, Nutter F, Evans A, Brown HK, Lefley DV, Barbaric I, Jones M, Ottewell PD. Loss of plakoglobin promotes decreased cell-cell contact, increased invasion and breast cancer cell dissemination in vivo. Breast Cancer Res. 2012;14(3):R86.

\footnotetext{
* Correspondence: P.D.Ottewell@shef.ac.uk

'Academic Unit of Clinical Oncology, Beech Hill Road, Sheffield, UK

${ }^{3}$ Academic Unit of Clinical Oncology, CR-UKMYCR Sheffield Cancer Research Centre, University of Sheffield, Sheffield S10 2RX, UK
} 


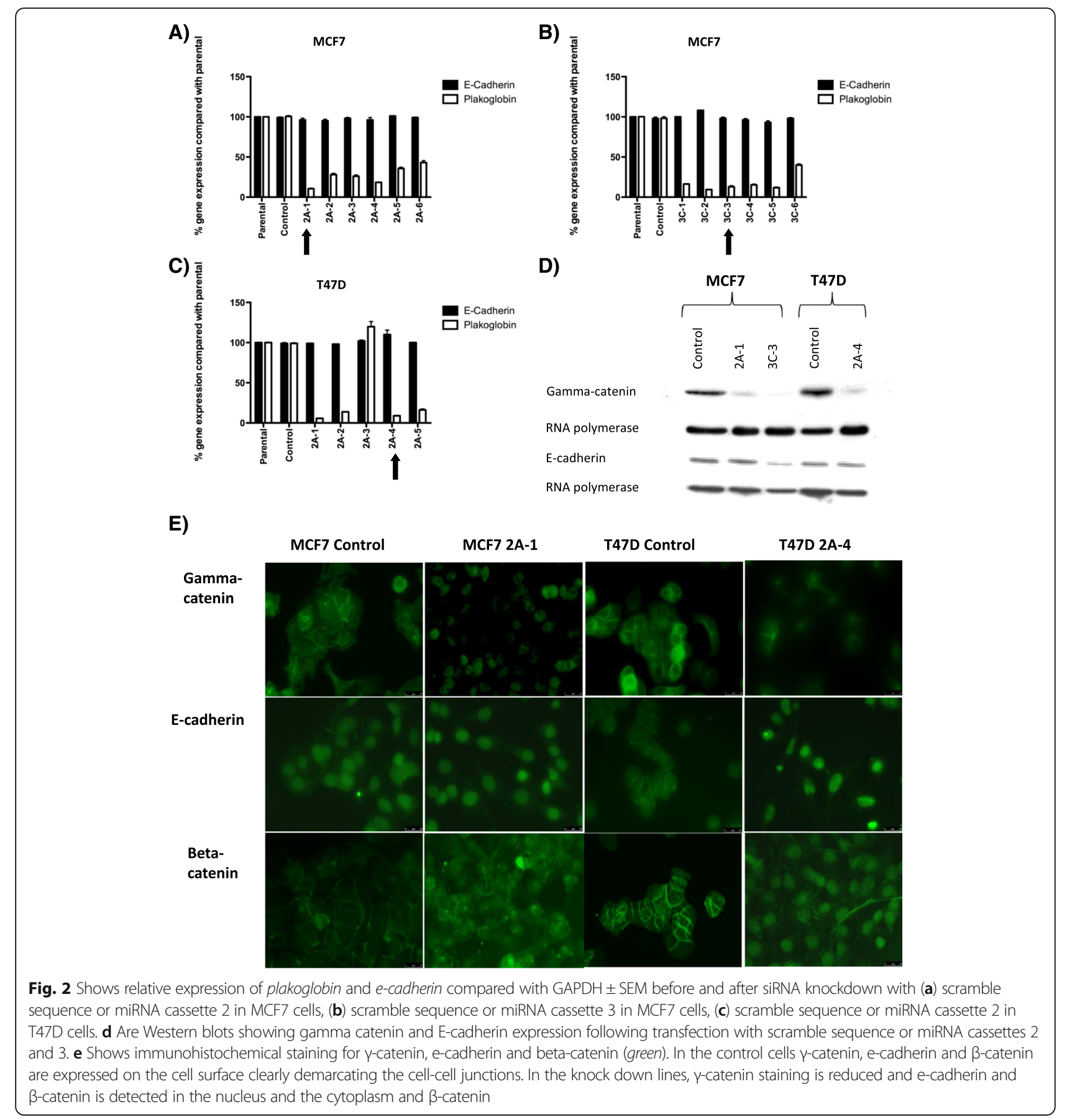

